\title{
Communications
}

\section{A Novel and Efficient Synthesis of Nitriles from Aldehydes under Solvent-free Microwave Irradiation Conditions}

\author{
Jong Chan Lee," Jae Man Yoon, and Jong Wook Baek \\ Department of Chemistr. Chung-Ang University, Seoul 156-756. Korea. E-mail: jclee acanack $k r$ \\ Received August 7. 2006
}

Key Words : $\Lambda$ dehydes, $\Lambda$ ldoximes, Anhydride, Microwave, Nitrile

\begin{abstract}
Nitriles are of importance as very uselul starting materials for the synthesis of a variety of biologically important heterocyclic compounds.' The direct transformation of aldehydes into the corresponding nitriles is one of the most fundamental and important reactions in organic transformations. ${ }^{2}$ Thus considerable efforts have been directed towards developing eflicient methods for the conversion of aldehydes into corresponding nitriles. Among the numerous methods to prepare nitriles, the dehydration of aldoximes has been served as one of the most useful method. Conventional methods lor the dehydration of aldoximes include the use of reagent systems such as alumina/methanesulionyl chloride, ${ }^{3}$ graphite/methanesulfonyl chloride, ${ }^{4}$ aluminium chloride/polassium iodide, $\mathrm{Nal} / \mathrm{MeCN},{ }^{6}$ alumia/PCl,${ }_{5}^{7}$ and $\mid \mathrm{RuCl}_{2}$ (p-cymenc) $\left.\right|_{2} /$ molecular sicves. ${ }^{8}$ [ lowever, above mentioned methods sullered from serious disadvantages
\end{abstract} which include harsh reaction conditions, long reaction times, low yields, use of exolic reagents and organic solvents.

Recently microwave irradiation technique has been utilized as a powerlul tool for the various organic transformations." The main benefits of performing reactions in microwave irradiation conditions are the significant enhancement of the reaction rates, yiclds, and sclectivity. In particular, the microwave irradiation conditions proved to be highly eflective to promote condensation reactions. "Thus, a couple of methods for the conversion of aldehydes to nitriles were recently reported utilizing microwave irtadiation technique. For examples, microwave promoted dehydration of aldoximes have been achicved by use of chemical reagents such as peroxymonosulfate/alumina, ${ }^{11}$ sodium hydrogen sulphate/ $\mathrm{SiO}_{2},{ }^{i 2}$ and IHY-Zeolite. ${ }^{13}$ However, these methods invariably utilized acidic or basic inorganic reagents and solid supports. In practice, the microwave induced methods utilizing solid supports often encountered with low reproducibility due to the heterogeneous nature of reaction conditions. Fut'hermore, regardless of conventional or microwave irradiation conditions, only few are applicable to produce nitriles from aldehydes without use of inorganic salts or solid supports.

Although many methods exist for the conversion of aldehydes into the corresponding nitriles, there has been no previous report on the use of microwave irradiation mediated method conducted in neat reaction conditions for the direct preparation of nitriles from aldehydes. Therefore it is highly desirable to develop practically applicable protocol for the conversion of aldehydes to nitriles using microwave

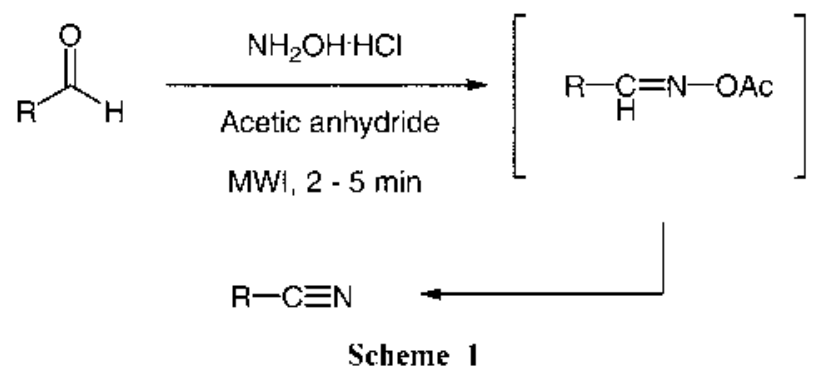

Table 1. Nitriles prepared from aldehydes under solvent-free microwave irradiation conditions

\begin{tabular}{|c|c|c|c|}
\hline Fintsy & $\mathrm{R}$ & Time (sec) & Yield (\%) \\
\hline 1 & $\mathrm{C}_{4} \mathrm{H}_{5-}$ & 300 & 88 \\
\hline 2 & $p-\mathrm{MeC}_{4} \mathrm{H}_{4-}^{-}$ & 180 & 92 \\
\hline 3 & $p$ - $\mathrm{MeOC} \mathrm{CH}_{1-}$ & 150 & 98 \\
\hline 4 & $p-\mathrm{ClC}_{6} \mathrm{H}_{4}-$ & 210 & 96 \\
\hline 5 & $p-\Gamma \mathrm{C}_{6} \mathrm{H}_{t}-$ & 210 & 85 \\
\hline 6 & $2.4-\mathrm{Cl}_{2} \mathrm{C}_{6} \mathrm{H}_{3}-$ & 210 & 85 \\
\hline 7 & $p-\mathrm{NO}_{2} \mathrm{C}_{4} \mathrm{H}_{4}-$ & 150 & 95 \\
\hline 8 & $\mathrm{CH}_{3}\left(\mathrm{CH}_{2}\right) ; \mathrm{CH}_{2-}$ & 210 & 78 \\
\hline 9 & $\mathrm{CH}_{3}\left(\mathrm{CH}_{2}\right)_{5} \mathrm{CH}_{2-}$ & 210 & 77 \\
\hline 10 & $\mathrm{C}_{\mathrm{S}} \mathrm{H}_{s} \mathrm{CH}=\mathrm{CH}-$ & 120 & 94 \\
\hline II & 3-Pyridyl & 120 & 98 \\
\hline 12 & 2-Thjophะne & 180 & 88 \\
\hline 13 & & 120 & 93 \\
\hline 14 & & 210 & 89 \\
\hline
\end{tabular}

"Isolated yields. 
irradiation in the homogeneous neat solvent-free media.

During the course of our research projects on development of environmentally friendlier synthetic methods for synthesis of heterocyclic compounds. we required a facile method for the preparation of nitriles. After tested various reagent syntems. we found that the acetic anhy'dride highly promotes the conversion of aldoxime intermediates into nitriles under microwave irradiation conditions. Acetic anhydride represents one of the most easily available and safe reagent in organic chemistry. Although acetic anhydride was occasionally utilized as a dehỵdration agent in some of organic transformations. ${ }^{14}$ its use in the direct conversion of aldehỵdes into corresponding nitriles has been unprecedented. Herein. we wish to disclose a new and eco-friendly preparative route to nitriles through direct treatment of aldehydes with hydrosylamine and acetic anhydride under solvent-free microwave irradiation conditions. The reactions were carried out by treating neat aldehy'des with 4.0 equiv of acetic anhydride and hydroxylamine hỵdrochloride under microwave irradiation using domestic microwave oven (Scheme 1). Closer inspection of the reaction conditions revealed that the use of four equivalents of acetic anhydride was necessary to obtain high yields and diminution of side-products. As shown in the Table 1 , the reaction could be easily applied to structurally diverse aldehydes to give the corresponding nitriles in excellent yields. This protocol was compatible with reactive substituents such as alkoxy and alkenyl compounds. The variation of electron donating and withdrawing substituents to the aromatic rings have no significant effects on the reaction rates and yields. In case of enolizable aliphatic aldehydes provided less satisfactory yields of aliphatic nitriles (entries 8-9). The present method probably proceed vio initial formation of $O$-acetylaldoxime intermediates. formed in situ by the reaction of aldoxime intermediates with acetic anhydride. followed by its decomposition under microwave irradiation conditions. In general procedure. aldehydes ( $1.0 \mathrm{mmol})$, hydroxylamine hydrochloride $(2.0$ mmol) and acetic anhỵdride $(4.0 \mathrm{mmol})$ were mixed thoroughly on a vortex mixer. The reaction mixture was placed in an alumina bath inside a domestic microwave oven (Samsung RE-21C. 850W) and irradiated 4-10 times for a period of $30 \mathrm{sec}$ with $20 \mathrm{sec}$ intervals. After completion of the reaction. the product mixture was dissolved in dichloromethane $(25 \mathrm{~mL})$ washed with water $(50 \mathrm{~mL})$, and dried over magnesium sulfate. After removal of the solvent the residue was purified by columın cluromatography (silica gel. dichloromethane : hexane $=1: 1$ ) to give the corresponding nitrile.

In conclusion we have developed a new and efficient method for the direct conversion of aldehydes into nitriles under microwave promoted neat solvent-free reaction conditions. The advantages of the present method in terms of facile manipulation, fast reaction rates. and formation of cleaner products under neat reaction conditions should make this protocol as a valuable alternative to the existing methods

Acknowledgment. This research was supported by the Chung-Ang University Research Grants in 2006.

\section{References and Notes}

1. (a) Wittenberger. S. T.: Donner. B. G. J. Ong. Chem. 1993. 58. 4139. (b) Chihiro. M.: Nagamoto. H.: Tekemura. I.: Kitano. K.: Komatsu. H; Sekiguchi. K.: Tabusa, F; Mori, T; Tominaga, M: Yabuuchi. Y. J. Med Chent 1995. 38. 353. (c) Fabiani. M. E. Drug New's Perspect. 1999. 12, 207.

2. Friedrich, K.: Wallentels. K. In The Chemistry of the Cyano Group Rappoport. Z., Ed: Interscience: New York, 1970. pp 9293.

3. Sharghi. H.: Sarvari. M. H. Tetrahedron 2002. 58.10323.

4. Sharghi. H.: Sarvari. M. H. Smthesis 2003. 243.

5. Boruah. M.: Konwar D. J. Org. Chem 2002, 67, 7138.

6. Ballini, R.: Fiorini. D.: Palmieri. A. Synlett 2003, 1841.

7. Niknam. K; Karami, B.: Kiasat. A. R. Bull. Korean Chem. Soc. 2005. 26.975

8. Yang. A. H.: Chang. S. Org. Letl 2001. 3. 4209

9. Microwones in Organic Sinhesis: Loupy. A.. Ed.: Wiley-VCH: Weinheim, 2002

10. Varma. R. S. Pun and Applied Chemistry 2001. 73.193

11. Bose. D. S.: Narasiah. A. V. Tetrahedron Lett. 1998. 39,6533

12. Das. B.: Madhusudhan. P.: Venkataiah. B. Smlen 1999. 1569.

13. Srinivas. K. V. N. S.: Reddy. B. E.: Das. B. Swlen 2002. 625.

14. (a) Bell. M. R.: Johnsont. T. R.: Wildi. B. S.: Woodward. R. B. J. Am. Chem Soc. 1958. 80. 1001. (b) Beringer, F. M.: Ugelow. I. $d$. Ant Chent Soc. 1953. 75. 2635. 